\title{
A novel deletion involving the connexin-30 gene, del(GJB6- d13s 1854), found in trans with mutations in the GJB2 gene (connexin-26) in subjects with DFNB1 non-syndromic hearing impairment
}

\author{
F J del Castillo, M Rodríguez-Ballesteros, A Álvarez, T Hutchin, E Leonardi, C A de Oliveira, \\ H Azaiez, Z Brownstein, M R Avenarius, S Marlin, A Pandya, H Shahin, K R Siemering, D Weil, \\ W Wuyts, L A Aguirre, Y Martín, M A Moreno-Pelayo, M Villamar, K B Avraham, H-H M Dahl, \\ M Kanaan, W E Nance, C Petit, R J H Smith, G Van Camp, E L Sartorato, A Murgia, F Moreno, I del \\ Castillo
}

$\mathrm{H}$ earing impairment is a common and highly heterogeneous sensory disorder. Genetic causes are thought to be responsible for more than $60 \%$ of the cases in developed countries. ${ }^{1}$ In the majority of cases, non-syndromic hearing impairment is inherited in an autosomal recessive pattern. $^{2}$ Thirty eight different loci and 20 genes for autosomal recessive non-syndromic hearing impairment (ARNSHI) have been identified to date.

In many populations, up to $50 \%$ of all cases of ARNSHI are caused by mutations in the DFNBI locus (MIM 220290) on 13q12. ${ }^{4}$ This locus contains the GJB2 gene (MIM 121011), encoding connexin-26 (Cx26), ${ }^{5}$ which belongs to a family of transmembrane proteins with about 20 members in humans. Hexamers of connexins (connexons) are displayed in the plasma membrane. Docking of connexons on the surfaces of two adjacent cells results in the formation of intercellular gap junction channels. ${ }^{6}$ Several different connexins, including Cx26, have been shown to participate in the complex gap junction networks of the cochlea. ${ }^{78}$ It has been postulated that these networks play a key role in potassium homeostasis, which is essential for the sound transduction mechanism. ${ }^{9}$

Given the high prevalence of DFNB1 deafness, molecular testing for GJB2 mutations has become the standard of care for the diagnosis of patients with non-syndromic hearing impairment of unknown cause ${ }^{10}$ However, the finding of a large number of affected subjects with only one GJB2 mutant allele complicates the molecular diagnosis of DFNBl deafness. In different studies, these have accounted for $10-50 \%$ of deaf subjects with GJB2 mutations. ${ }^{4}$ It was hypothesised that there could be other mutations in the DFNBI locus but outside the GJB2 gene. This hypothesis gained support by the finding of a deletion in the DFNB1 locus outside GJB2 but truncating the neighbouring GJB6 gene (MIM 604418), which encodes connexin-30 ( $\mathrm{C} \times 30)$, another component of the gap junction networks of the cochlea. This deletion, named del(GJB6-D13S1830), was found in affected subjects either in homozygosity or in double heterozygosity with a GJB2 mutation. ${ }^{11-13}$ Isolation and sequencing of the deletion breakpoint junction revealed the loss of a DNA segment initially thought to be $342 \mathrm{~kb}$ in size but currently estimated to be $309 \mathrm{~kb} .^{12}{ }^{14}$

In a multicentre study, it was shown that the $\operatorname{del}(G J B 6-$ D13S1830) mutation is most frequent in Spain, France, the United Kingdom, Israel, and Brazil (5.9-9.7\% of all DFNBI alleles); it is less frequent in the USA, Belgium, and Australia (1.3-4.5\% of all DFNB1 alleles), and is very rare in southern

\section{Key points}

- DFNB1 deafness, caused by mutations in the gene encoding connexin-26 (GJB2), is the most frequent subtype of autosomal recessive non-syndromic hearing impairment. Molecular testing for GJB2 mutations has become a standard diagnostic approach for subjects with this disorder. However, 10-50\% of affected subjects with GJB2 mutations carry only one mutant allele.

- A 309 kb deletion truncating the GJB6 gene (encoding connexin-30) was shown to be the accompanying mutation in up to $50 \%$ of deaf GJB2 heterozygotes in different populations. We report the molecular characterisation of the breakpoint junction of a novel 232 $\mathrm{kb}$ deletion in the DFNB1 locus, del(GJB6-D13S1854), which was also found in trans with pathogenic GJB2 mutations in affected subjects. The deletion arose by unequal homologous recombination, involving an AluY sequence inside GJB6 intron 2, a mechanism which might generate other deletions at DFNB1.

- We developed a novel diagnostic test for the combined detection of del(GJB6-D13S1830) and this new del(GJB6-D13S1854) in a single PCR assay. The del(GJB6-D13S1854) mutation accounts for $25.5 \%$ of the affected GJB2 heterozygotes which remained unresolved after screening for del(GJB6-D13S1830) in Spain, 22.2\% in the UK, 6.3\% in Brazil, and $1.9 \%$ in northern Italy. It was not found in affected GJB2 heterozygotes from France, Belgium, Israel, the Palestinian Authority, USA, or Australia.

- Haplotype analysis revealed a common founder for the mutation in Spain, Italy, and the UK. Our data further support the complexity of the genetic epidemiology of non-syndromic hearing impairment.

Italy. ${ }^{14}$ Recent studies have found, however, that the deletion is present in northern Italy at frequencies similar to those of other European countries ( ${ }^{15}$ and Murgia A, Leonardi E,

Abbreviations: ARNSHI, autosomal recessive non-syndromic hearing impairment 
unpublished data). The deletion was also found in other studies in the USA ${ }^{16-19}$ and Germany, ${ }^{20}$ but not in Austria, ${ }^{21}$ Turkey, ${ }^{22}{ }^{23}$ or China. ${ }^{24}$ Although the finding of the del(GJB6D13S1830) mutation provided an explanation for the hearing impairment in as many as $30-70 \%$ affected GJB2 heterozygotes in some populations, it has become evident that other DFNBI mutations remain to be identified in most countries. ${ }^{14}$ Here we report the molecular characterisation of a novel deletion, also truncating the GJB6 gene, but resulting in the loss of a DNA segment shorter than in $\operatorname{del}(G J B 6-D 13 S 1830)$.

\section{METHODS}

This study was done on probands with ARNSHI and their relatives from Spain, Italy, France, Belgium, the United Kingdom, Israel, the Palestinian Authority, the USA, Brazil, and Australia. After getting written informed consent, blood samples were obtained and DNA was extracted by standard procedures.

Novel microsatellite markers were developed in the DFNBI region by searching for tandem repeats of the CA dinucleotide in sequence contig NT_024524.13 (National Center for Biotechnology Information database, Homo sapiens genome view, build 34) and by designing flanking primers:

- marker Dl3S1853: forward primer 5'-CAGACTGGCACAAACTTAACTG-3'; reverse primer, 5'-TGTACATCTCTTCTTACATTCATGT-3' (annealing temperature, $56^{\circ} \mathrm{C}$ );

- marker D13S1854: forward primer, 5'-CTCCATCCTGGGTGACAGAGTGAG-3'; reverse primer, 5'-AGGAAGAGCTGGGGTTGCTAAGAA-3' (annealing temperature, $58^{\circ} \mathrm{C}$ ).

A

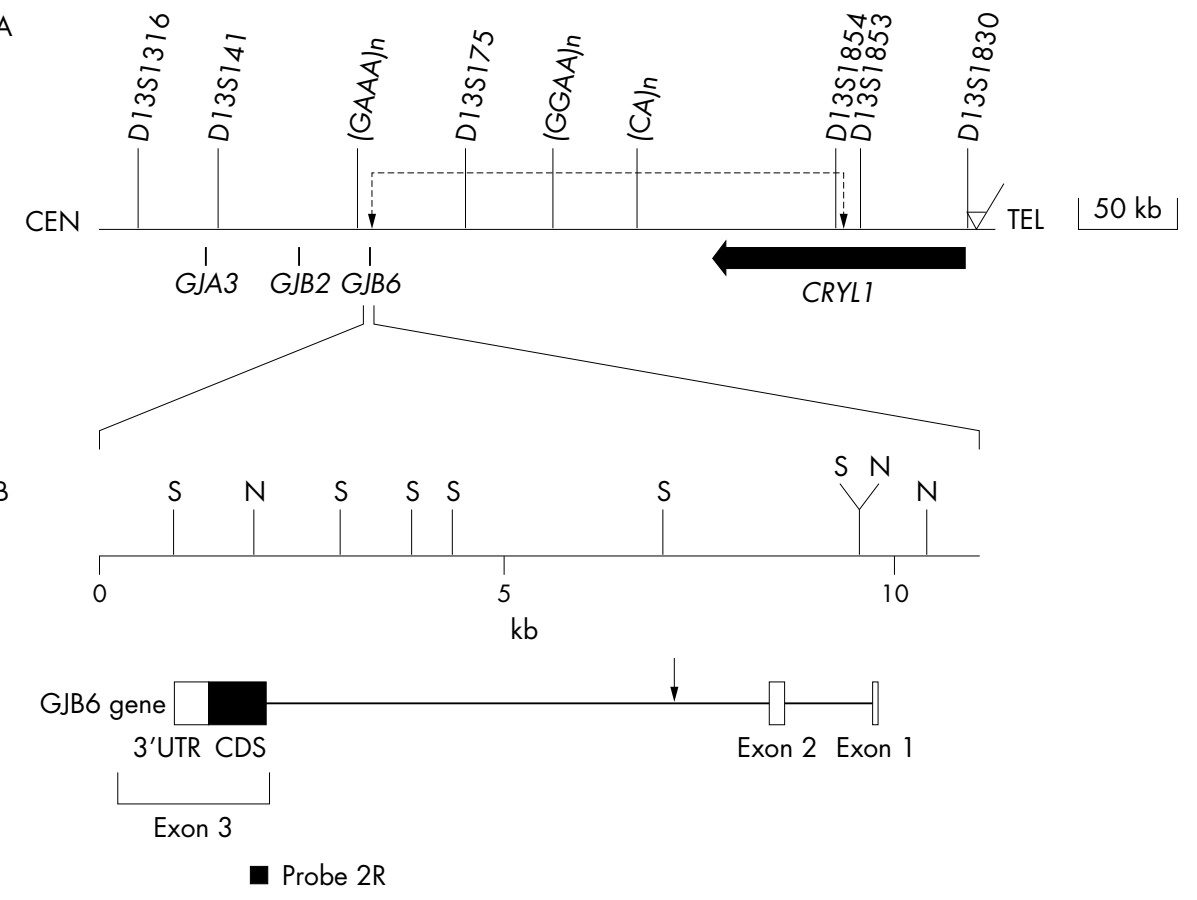

C

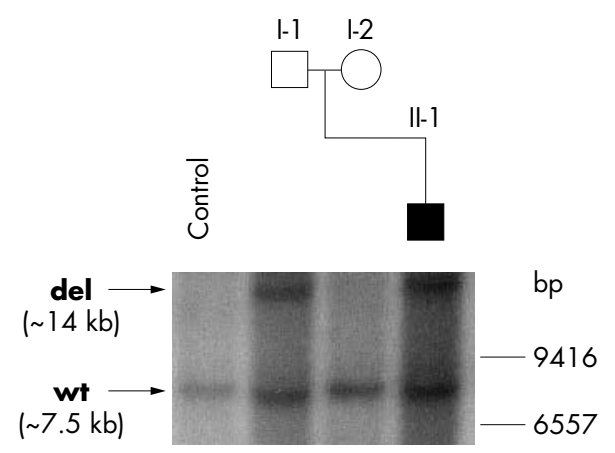

Figure 1 Map of the DFNB1 region on 13q12, and Southern blot analysis of family E079. (A) Map of a $600 \mathrm{~kb}$ DNA segment including the DFNB 1 locus. The positions of polymorphic genetic markers are indicated by vertical bars. Genes in the region are depicted as horizontal bars or arrows. GJA3 encodes connexin-46 (MIM 121015) and CRYL1 codes for $\lambda$-crystallin. The two breakpoints of the del(GJB6-D13S1854) mutation are marked by vertical arrows, and the extent of the deletion is indicated by the dashed line. An empty arrowhead indicates the distal end of the previously reported del(GJB6-D13S1830) mutation. (B) Physical map of a $10 \mathrm{~kb}$ DNA segment containing the GJB6 gene. Restriction sites are indicated by vertical bars. N, Nsil; S, Sspl. The structure of the GJB6 gene is shown below the map. Exons are depicted as boxes, introns as thin lines. 3'-UTR, 3' untranslated region; CDS, GJB6 coding region. A vertical arrowhead marks the deletion breakpoint internal to GJB6. The position of probe 2R, used in the Southern blot analysis, is indicated below the gene. (C) Southern blot analysis of family E079 with probe 2R on Nsil digests of genomic DNA. Polymerase chain reaction amplification of probe $2 \mathrm{R}$ and Southern blotting experiments were carried out as reported. ${ }^{12}$ An approximately $7.5 \mathrm{~kb}$ band (wt) is revealed in all subjects of family EO79 and in the control. In addition, a novel $14 \mathrm{~kb}$ band (del), created by the deletion, is revealed in affected subject II: 1 (double heterozygote, 35delG in GJB2/del(GJB6-D13S1854)), and in his father, I: 1 (del(GJB6-D13S1854) carrier). This band is absent in the control subject and in the proband's mother, l:2 (35delG carrier). 
A
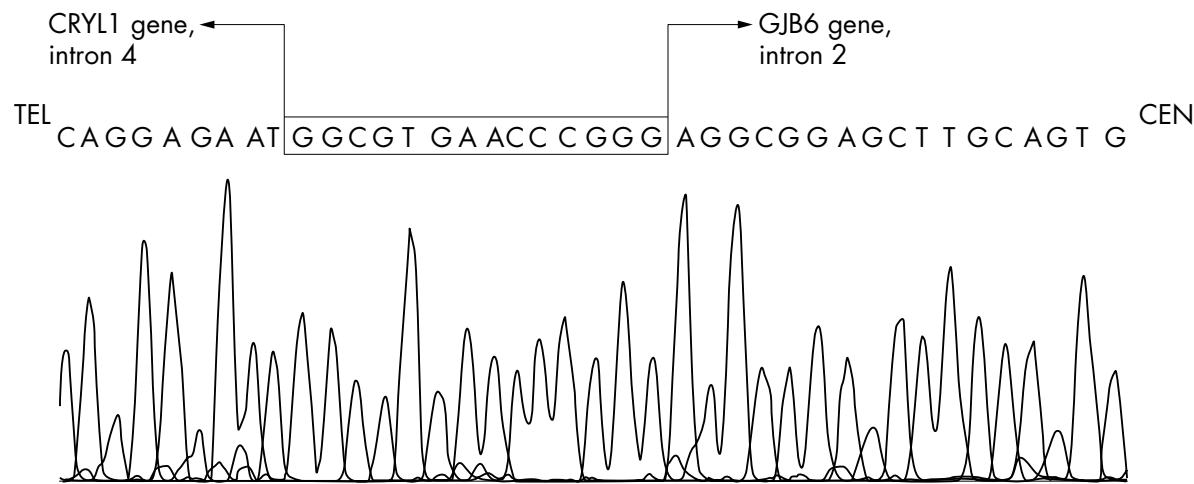

B

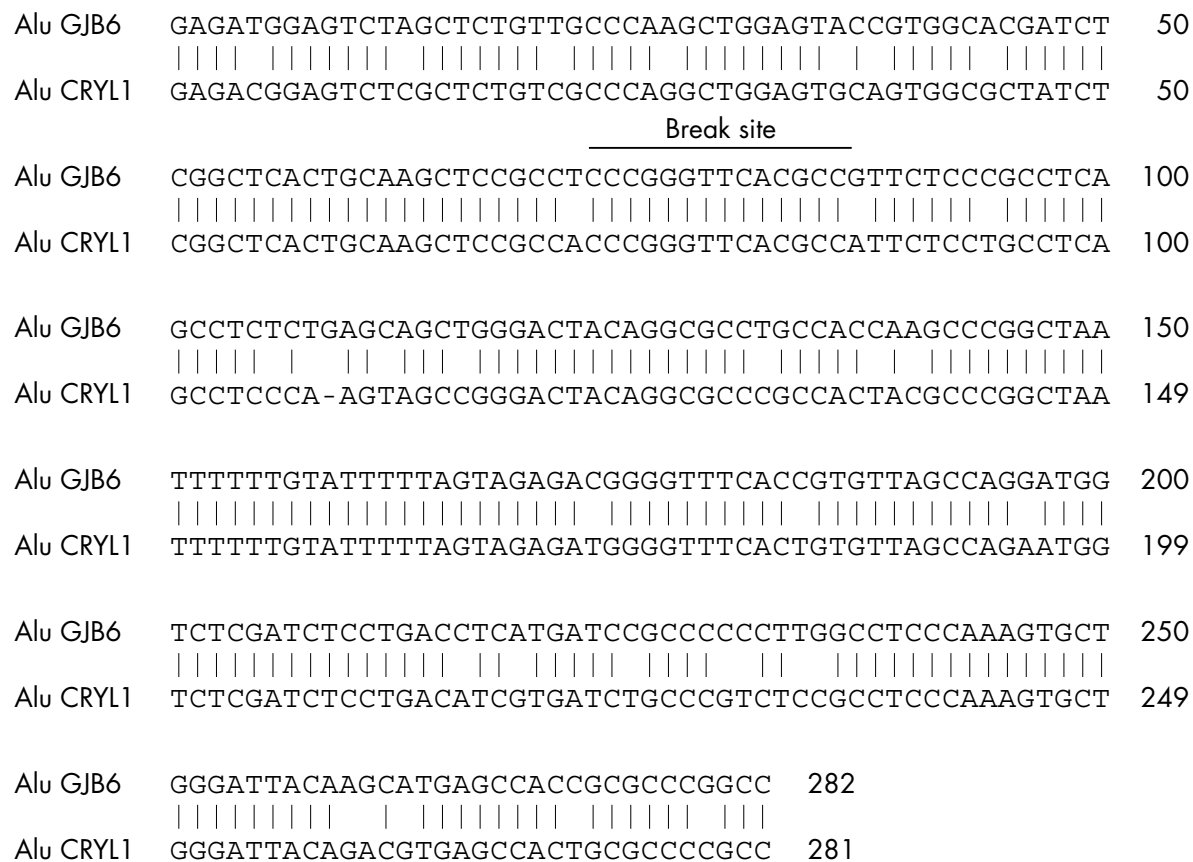

Figure 2 Breakpoint junction of the del(GJB6-D13S1854) deletion. Sequencing of the breakpoint junction was done directly on the polymerase chain reaction product obtained with primers DelBK1 and DelBK2. We used sequencing primer DelBK3, 5'-TCTTCTGTATGTATGTCACTTTCA-3'. (A) Electropherogram of a DNA segment containing the breakpoint junction (boxed) and flanking sequences. The relative positions of the centromere (cen) and telomere (tel) of the long arm of chromosome 13 are indicated to show the orientation of the sequenced DNA segment. (B) Alignment of the sequences flanking the proximal and distal deletion breakpoints. The alignment was performed using BLASTN software (National Center for Biotechnology Information), which reported an identity of $88 \%$ along 282 nucleotides.

\section{RESULTS}

We reported previously on 39 unrelated Spanish subjects with ARNSHI, who were heterozygous for one GJB2 mutant allele and did not carry the del (GJB6-D13S1830) mutation. ${ }^{14}$ All these cases carried alleles which are considered unambiguously pathogenic. ${ }^{10}$ After excluding 11 cases not linked to DFNBI on the basis of haplotype analysis of siblings, there remained 28 unelucidated heterozygotes. ${ }^{14}$ We genotyped the proband, parents, and siblings from these 28 cases for microsatellite markers D13S175 ${ }^{25}$ and D13S1830, ${ }^{26}$ both of which are deleted in the $\operatorname{del}(G J B 6-D 13 S 1830)$ mutation (fig 1A). In two multiplex cases (S591, S630) and two simplex cases (E079, E262), haplotype analysis revealed inconsistencies in the segregation of alleles of marker D13S175, suggesting the presence of an unamplifiable allele. The same results were obtained when using an alternative primer pair ${ }^{12}$ flanking the microsatellite at D13S175.
Conversely, haplotype analysis revealed no segregation inconsistencies, but there was heterozygosity for marker D13S1830 in either the proband or the parents of all four cases. Together, these data suggested the existence of (at least) a novel deletion at the DFNBI locus, involving marker D13S175 but not D13S1830.

To simplify the search for the deletion breakpoints, we assumed that the deletion in these four cases would be the same. Haplotype analysis for other microsatellite markers from the DFNBI locus ${ }^{11}$ (fig lA) revealed inconsistencies in the segregation of alleles, which allowed us to map the telomeric breakpoint distal to $(\mathrm{CA})_{\mathrm{n}}$, and the centromeric breakpoint between markers (GAAA) ${ }_{\mathrm{n}}$ and D13S175. These results suggested that the centromeric breakpoint could be inside the GJB6 gene. We tested this hypothesis by Southern blotting (fig 1, panels B and C). Probe 2R was assayed on Ssp I digests of genomic DNA from the proband and parents of 
case E079 in order to investigate whether the GJB6 coding region, fully contained in exon 3 (fig $1 \mathrm{~B}$ ), was intact. This probe did not show any change in dosage of GJB6 exon 3 or in the $S s p$ I restriction pattern when comparing deletion carriers with control subjects (data not shown). To investigate whether the deletion could involve other parts of the GJB6 gene, we assayed probe $2 \mathrm{R}$ on NsiI digests of genomic DNA from deletion carriers and control subjects (fig 1, panels $B$ and C). In addition to the expected $7.5 \mathrm{~kb}$ band, a novel $14 \mathrm{~kb}$ band, created by the deletion, was observed in the deletion carriers (fig lC). As this $14 \mathrm{~kb}$ band has the expected size based upon the predicted restriction map, these findings led us to conclude that the deletion truncated GJB6.

To locate the deletion distal breakpoint, we searched for novel microsatellite markers in the interval between $(C A)_{n}$ and D13S1830 (see Methods). In all four cases with the deletion, genotyping and haplotype analysis revealed heterozygosity and consistent segregation for marker D13S1853, but inconsistencies in the segregation of alleles of marker D13S1854 (fig 1A). These data placed the distal deletion breakpoint between D13S1854 and D13S1853, an interval of about $9.5 \mathrm{~kb}$. Thus we undertook a BLASTN comparison of the sequence stretch containing GJB6 intron 1, exon 2, and intron 2 with the sequence spanning the interval between D13S1854 and D13S1853. This analysis revealed the existence of a 282 bp Alu sequence inside GJB6 intron 2 sharing $88 \%$ identity with another Alu repeat located in direct orientation inside the D13S1854-D13S1853 interval. We designed primers flanking this candidate breakpoint junction, and a polymerase chain reaction (PCR) product of about $560 \mathrm{bp}$ was obtained only from DNA samples of deletion carriers. Sequencing of this PCR product revealed the deletion breakpoint junction (fig 2A), which was the same in all four studied cases.

This novel deletion was named del(GJB6-D13S1854). Examination of the breakpoint junction supported the hypothesis that it originated from homologous recombination between two Alu sequences which belong to the Y subfamily, as shown by RepeatMasker software ${ }^{27}$ (fig 2B). The proximal repeat is located in GJB6 intron 2, and the distal repeat is in intron 4 of the gene encoding $\lambda$-crystallin (CRYL1, GenBank AF077049). The exact breakpoints could not be determined as the breaks could have taken place at any point of two identical $14 \mathrm{bp}$ stretches (fig 2B). The deletion spans

A
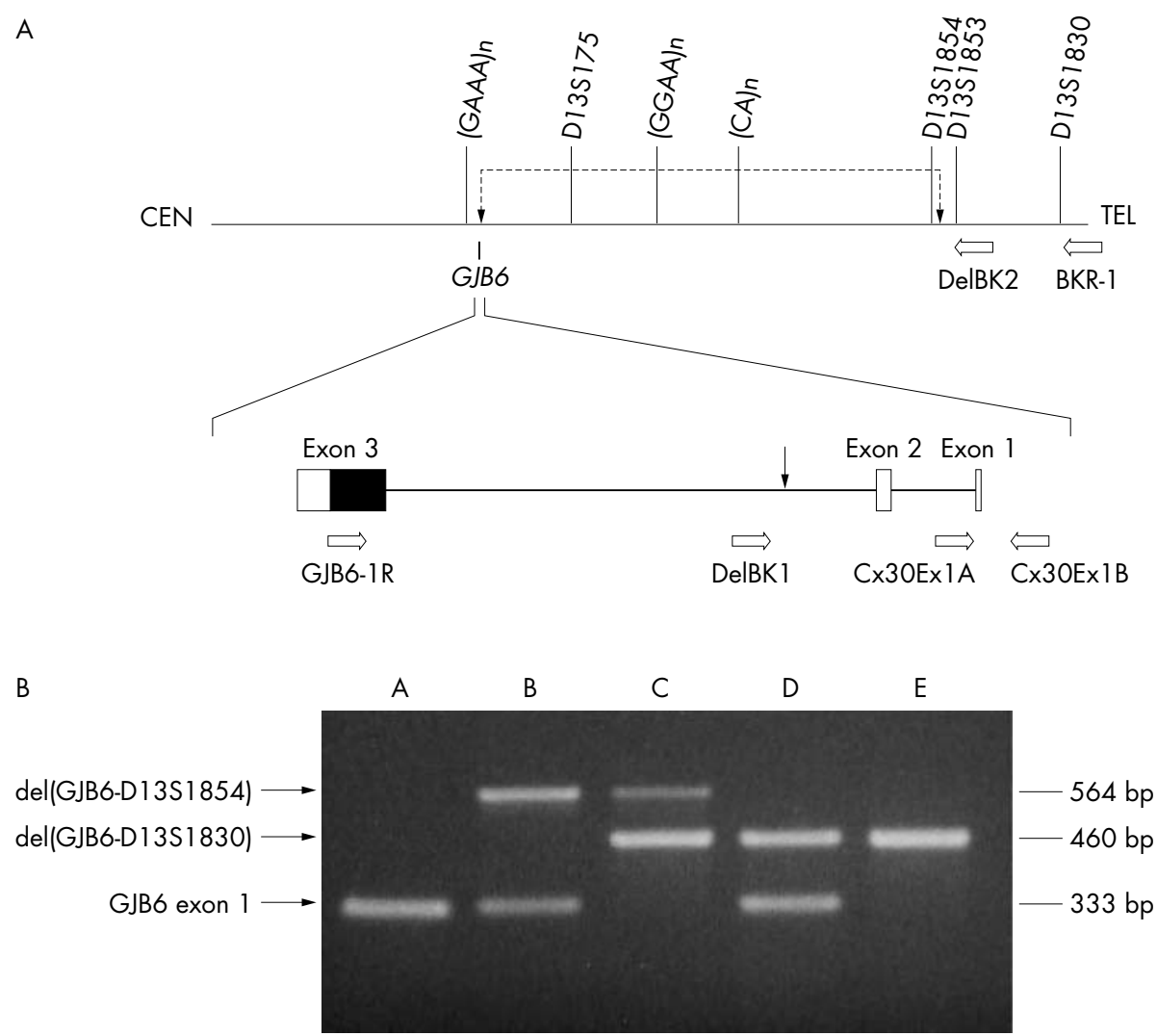

Figure 3 Single test for the detection of del(GJB6-D13S1830) and del(GJB6-D13S1854). The rationale of the method is to amplify DNA segments containing the breakpoint junction of each deletion, as well as a segment containing GJB6 exon 1, which is used as a control to check the efficiency of the polymerase chain reaction (PCR) and to distinguish heterozygosity $v$ homozygosity for any of the two deletions (GJB6 exon 1 is removed by both deletions). (A) Schematic drawing showing the location of the primers used in the multiplex PCR assay. GJB6-1R, 5'-

TITAGGGCATGATTGGGGTGATT1-3', and BKR-1, 5'-CACCATGCGTAGCCTTAACCATTTT-3' (for amplification of the del(GJB6-D13S1830) breakpoint junction); DelBK1, 5'-TCATÁGTGAAGAACTCGATGCTGTTT-3', and DelBK2, 5' -CAGCGGCTACCCTAGTGTGGT-3' (for amplification of the del(GJB6-D13S1854) breakpoint junction); Cx30Ex1A, 5'-CGTCTTTGGGGGTGTTGCTT-3', and Cx30Ex1B, 5'-

CATGAAGAGGGCGTACAAGTAAGAA-3' (to amplify GJB6 exon 1). PCR was carried out using the following programme: one cycle of denaturation at $95^{\circ} \mathrm{C}$ for five minutes; five touchdown cycles of denaturation at $94^{\circ} \mathrm{C}$ for 40 seconds, and annealing for 40 seconds at $65^{\circ} \mathrm{C}$ for the first cycle and a $1{ }^{\circ} \mathrm{C}$ reduction per cycle; 25 cycles of denaturation at $94^{\circ} \mathrm{C}$ for 40 seconds, and annealing at $60^{\circ} \mathrm{C}$ for 40 seconds; and a final extension step of $72^{\circ} \mathrm{C}$ for seven minutes. The reaction took place in a final volume of $15 \mu \mathrm{l}$, at a final concentration of $1.5 \mathrm{mM} \mathrm{MgCl}$, using Fast Start Taq DNA polymerase (Roche). (B) Separation of the PCR products by electrophoresis in a 1.5\% agarose gel. The position of the PCR products corresponding to the deletion breakpoint junctions and to GJB6 exon 1 are indicated by arrows on the left, and their sizes in base pairs (bp) are shown on the right. All the PCR products obtained in this multiplex reaction were sequenced to confirm their identities and validate the test. A, Wild type (wt); B, del(GJB6-D13S1854)/ wt heterozygote; C, del(GJB6-D13S1830)/del(GJB6-D13S1854) compound heterozygote; D, del(GJB6-D13S1830)/wt heterozygote; E, del(GJB6D13S1830) homozygote. 
Table 1 Results from the screenings for the del(GJB6-D13S1854) mutation

\begin{tabular}{lll}
\hline Country/laboratory & $\begin{array}{l}\text { No of DFNB1 heterozygotes carrying } \\
\text { del(GJB6-D13S1854)/No of DFNB 1 } \\
\text { heterozygotes }\end{array}$ & $\begin{array}{l}\text { Accompanying DFNB1 mutant allele } \\
\text { (No of cases) }\end{array}$ \\
\hline Spain & $12 / 47(25.5 \%)$ & 35delG (10), V371 (1), del(GJB6- \\
& $1 / 53(1.9 \% 1830)(1)$ \\
Italy & $0 / 40$ & $35 \mathrm{delG}(1)$ \\
France & $0 / 20$ & \\
Belgium & $4 / 18(22.2 \%)$ & $35 \mathrm{delG}(4)$ \\
United Kingdom & $0 / 11$ & \\
Israel & $0 / 92$ & \\
USA/Virginia & $0 / 88$ & V37I (1) \\
USA/lowa & $1 / 16(6.3 \%)$ & \\
Brazil & $0 / 27$ & \\
Australia & & \\
\hline
\end{tabular}

$232 \mathrm{~kb}$. It could create a chimeric gene by joining CRYL1 intron 4 with GJB6 intron 2. The hypothetical chimeric mRNA would contain the first three exons of CRYL1 and GJB6 exon 3. However, no product is likely as there is an in-frame stop codon in between the two open reading frames.

We developed a single test for the detection of both deletions, which is useful for routine molecular diagnosis (fig 3). The del (GJB6-D13S1854) mutation was found in trans in 12 of 47 Spanish unrelated affected subjects which were unresolved DFNBI heterozygotes $(25.5 \%)$ (table 1). Their hearing impairments ranged from mild to profound. Interestingly, one subject was a compound heterozygote for the two deletions (fig 3, lane C). We also screened 604 additional Spanish unrelated subjects with ARNSHI who were not carriers of DFNBI mutations. One of these was found to be heterozygous for $\operatorname{del}(G J B 6-D 13 S 1854)$. The deletion was not found in 100 control subjects with normal hearing. After this screening, the unelucidated heterozygotes in our sample represent $12.2 \%$ of the total number of subjects with at least one DFNBI mutation (36/295). Excluding 11 cases not linked to DFNB1, this figure drops to $8.5 \%$ (25/295). With a frequency of $2.2 \%$ (12/548), the $\operatorname{del}(G J B 6-D 13 S 1854)$ mutation is among the five most common DFNBI alleles in our Spanish sample.

A multicentre study was conducted to investigate the prevalence of the novel deletion in different countries (table 1). The del(GJB6-D13S1854) mutation was found to account for $22.2 \%$ of affected GJB2 heterozygotes who were unresolved after screening for $\operatorname{del}(G J B 6-D 13 S 1830)$ in the United Kingdom, for $6.3 \%$ in Brazil, and for $1.9 \%$ in northern Italy. It was not found in screening carried out on samples from France, Belgium, Israel, the USA, or Australia. The novel deletion was not found in 159 Israeli Jewish and 40
Palestinian Arab unrelated subjects with ARNSHI, who did not carry any GJB2 mutation.

DNA sequencing confirmed that the breakpoint junction was the same in all the positive cases found in Spain, Italy, the United Kingdom, and Brazil. We investigated the evolutionary origins of the deletion by studying haplotypes associated with this mutation (table 2). All chromosomes carrying the deletion share a core haplotype composed of allele 209 from marker (GAAA) (frequency of this allele in Spain, 0.415), and allele 204 of marker D13S1853 (frequency of this allele in Spain, 0.411) (table 2). These markers are very close to the deletion breakpoints, at distances of only 9 and $6 \mathrm{~kb}$, respectively. An expanded haplotype with all the four markers revealed four variants associated with the deletion, the most frequent being haplotype A, from which the other three could have arisen through single recombination events (table 2). Our results show that all the studied chromosomes carrying the del (GJB6-D13S1854) mutation in Spain, the United Kingdom, and Italy share a common founder.

\section{DISCUSSION}

The hypothesis of digenic inheritance of DFNBl hearing impairment has received theoretical support from several observations. Both Cx26 and Cx30 are expressed in the same inner ear structures. ${ }^{28}{ }^{29}$ Moreover, connexons composed of Cx26 can bind connexons composed of Cx30 to form heterotypic gap junction channels. ${ }^{30}$ It was also reported that a GJB6 mutation results in autosomal dominant hearing impairment in humans, ${ }^{31}$ and that $\mathrm{C} \times 30$ deficient mice lack the endocochlear potential and have a severe constitutive hearing impairment. ${ }^{32}$ However, the fact that point mutations in GJB6 have not yet been found in cases of ARNSHI in

Table 2 Haplotypes associated with the del(GJB6-D13S1854) mutation

\begin{tabular}{|c|c|c|c|c|c|c|}
\hline \multirow[b]{2}{*}{ Marker† } & \multirow[b]{2}{*}{ Heterozygosity $¥$ (\%) } & \multicolumn{4}{|c|}{ Haplotype* $^{*}$} & \multirow{2}{*}{$\begin{array}{l}\text { Genotype for CEPH individua } \\
134702\end{array}$} \\
\hline & & A & B & C & D & \\
\hline$(\mathrm{TG})_{\mathrm{n}}$ & 65 & 208 & 204 & 206 & 208 & $206 / 208$ \\
\hline$(G A A A)_{n}$ & 79 & 209 & 209 & 209 & 209 & $209 / 216$ \\
\hline D13S1853 & 66 & 204 & 204 & 204 & 204 & $202 / 202$ \\
\hline D13S1830 & 71 & 153 & 153 & 153 & 156 & $153 / 156$ \\
\hline \multirow{3}{*}{\multicolumn{2}{|c|}{$\begin{array}{l}\text { Number and geographical distribution of } \\
\text { haplotypes }(n=14)\end{array}$}} & 6 Spain & 1 Spain & 1 Spain & 2 Spain & \\
\hline & & 2 UK & 1 UK & & & \\
\hline & & Total: 9 & Total: 2 & Total: 1 & Total: 2 & \\
\hline
\end{tabular}

*We only report here those cases in which the haplotype associated with the deletion could be determined unambiguously. Allele sizes were determined by DNA sequencing of a control sample, which was used as a standard in genotyping assays. To allow other laboratories to compare their data with those reported in this work, we provide allele sizes for individual 134702, available from $\mathrm{CEPH}^{25}$

tRelative order and physical distances are as follows: $(\mathrm{TG})_{n}-110 \mathrm{~kb}-(\mathrm{GAAA})_{n}-9 \mathrm{~kb}$ - deletion proximal breakpoint - $232 \mathrm{~kb}$ - deletion distal breakpoint $6 \mathrm{~kb}-\mathrm{D} 13 \mathrm{~S} 1853-60 \mathrm{~kb}-\mathrm{D} 13 \mathrm{~S} 1830$.

†Calculated from 100 Spanish control chromosomes. 
humans argues against this hypothesis. In addition, $\mathrm{C} \times 26^{+/-} /$ $\mathrm{C} \times 30^{+/-}$double heterozygous mice have only a moderate hearing impairment, ${ }^{33}$ in contrast with the phenotype observed in humans, where most double heterozygotes for $\operatorname{del}(G J B 6-D 13 S 1830)$ and a GJB2 mutation have severe or profound hearing impairment. ${ }^{11-13} 151619203435$

An alternative hypothesis postulates the existence of a cis acting regulatory element which would activate the expression of GJB2 in the inner ear. This regulatory element would have been removed by the deletions, and its absence would have dramatic effects on the expression of GJB2, to the point that an otherwise normal allele would behave as a null allele. Both hypotheses can be combined-that is, the main pathogenic effect of the deletions might be caused by the GJB2 expression deficit, but haploinsufficiency for Cx30 may contribute to worsening of the phenotype.

The $232 \mathrm{~kb}$ sequence stretch removed by del(GJB6D13S1854) is still too large to search for a regulatory element. Molecular characterisation of other DNA rearrangements in the DFNB1 locus leading to hearing impairment may help to define a smaller interval. Under the hypothesis of the regulatory element, it is predicted that another class of deletions, leading to hearing impairment but not truncating GJB6, might also be present in the DFNB1 locus. After screening for the deletions so far reported, affected GJB2 heterozygotes still represent $8-30 \%$ of all subjects with mutations in GJB2 in different populations ( ${ }^{14}$ and this study). These figures are far from what should be expected if these GJB2 heterozygotes were just coincidental carriers. Although hypothetical epistatic interactions between GJB2 mutations and other unlinked gene(s) might contribute to this situation, additional mutations in DFNBI, not yet identified, are also likely to exist. The AluY sequence contained in GJB6 intron 2 has the potential of generating deletions affecting this gene, by homologous recombination with other highly similar repeats along the DFNBI locus. Alu/ Alu recombination leading to deletion is a common disease causing mechanism. ${ }^{36}$

Both del(GJB6-D13S1830) and del(GJB6-D13S1854) inactivate the CRYL1 gene and remove the sequence interval between GJB6 and CRYL1, where no additional genes have been reported so far. The CRYLI gene is widely expressed, and its product, $\lambda$-crystallin, shows similarity with 3 -hydroxyacylCoA dehydrogenase. ${ }^{37}$ The contribution of $\lambda$-crystallin to DFNBl hearing impairment, if any, remains enigmatic. To date, subjects carrying either $\operatorname{del}(G J B 6-D 13 S 1830)$ or $\operatorname{del}(G J B 6-D 13 S 1854)$ do not present with any eye disorder ( ${ }^{12}$ and this study).

Our multicentre study reveals significant differences in the frequency of each of the deletions, and also different patterns of geographical distribution. The $\operatorname{del}(G J B 6-D 13 S 1830)$ mutation, found in many populations over the world, is much more frequent than $\operatorname{del}(G J B 6-D 13 S 1854)$, which is for the present restricted to a few countries. Both mutant alleles are frequent in Spain and the United Kingdom (the combined frequency of the two deletions in our Spanish sample is $10.6 \%(58 / 548)$ of the DFNBI mutant alleles; in the United Kingdom they total $9.8 \%$ of the DFNBI alleles and both are among the five most common mutations); in France, $\operatorname{del}(G J B 6-D 13 S 1830)$ is very frequent, whereas $\operatorname{del}(G J B 6-$ D13S1854) has not been found to date; and in Belgium, $\operatorname{del}(G J B 6-D 13 S 1830)$ is not a common allele, while del(GJB6D13S1854) has not been detected so far ( ${ }^{14}$ and this study). The situation in Italy is even more striking, the del(GJB6D13S1830) being a frequent allele in the north and very rare in the south $\left({ }^{14} 15\right.$ and Murgia A, Leonardi E, unpublished data). These differences between neighbouring countries, and even between regions of the same country, further illustrate the complexity of the genetic epidemiology of nonsyndromic hearing impairment.

\section{Authors' affiliations}

F J del Castillo*, M Rodríguez-Ballesteros*, A Álvarez, L A Aguirre, Y Martín, M A Moreno-Pelayo, M Villamar, F Moreno, I del Castillo, Unidad de Genética Molecular, Hospital Ramón y Cajal, Madrid, Spain

D Weil, C Petit, Unité de Génétique des Déficits Sensoriels INSERM

U587, Institut Pasteur, Paris, France

T Hutchin, Clinical Chemistry, Birmingham Children's Hospital, Birmingham, UK

E Leonardi, A Murgia, Department of Paediatrics, University of Padua, Padua, Italy

C A de Oliveira, E L Sartorato, Centro de Biologia Molecular e Engenharia Genética (CBMEG), Universidade Estadual de Campinas, Sâo Paulo, Brazil

H Azaiez, M R Avenarius, R J H Smith, Interdepartmental Human Genetics Program and the Department of Otolaryngology, University of lowa, lowa City, lowa, USA

Z Brownstein, K B Avraham, Department of Human Genetics and

Molecular Medicine, Sackler School of Medicine, Tel Aviv University, Tel Aviv, Israel

S Marlin, Unité de Génétique Médicale, Hôpital Trousseau, Paris, France A Pandya, W E Nance, Department of Human Genetics, Medical College of Virginia of Virginia Commonwealth University, Richmond, Virginia, USA

H Shahin, M Kanaan, Life Sciences Department, Bethlehem University, Bethlehem, Palestinian Authority

K R Siemering, The Murdoch Children's Research Institute, Royal Children's Hospital, Melbourne, Australia

W Wuyts, G Van Camp, Department of Medical Genetics, University of Antwerp, Antwerp, Belgium

H-H M Dahl, Department of Paediatrics, University of Melbourne, Melbourne, Australia

*These authors contributed equally to this work

We thank the patients and their relatives for their kind cooperation in this study, and FIAPAS for their enthusiastic support of this research. FJdC and $M V$ were recipients of fellowships from the Comunidad de Madrid. $M R B$ and AA were recipients of fellowships from Fondo de Investigaciones Sanitarias. LA was a recipient of a fellowship from the Organización Nacional de Ciegos Españoles. This work was supported by grants from the European Community (QLG2-CT-1999-00988), CAICYT of Spanish Ministerio de Ciencia y Tecnología (SAF200203966, to FM), Spanish Research Network on the Genetic and Molecular Bases of Hearing Disorders (FIS G03/203, to FM), Programa Ramón y Cajal (to IdC), Spanish Fondo de Investigaciones Sanitarias (FIS PI020807, to IdC), the Israel Ministry of Science and Technology (to KBA), and the National Institutes of Health (RO1DC02842, to RJHS).

Competing interests: none declared

Correspondence to: Dr Ignacio del Castillo, Unidad de Genética Molecular, Hospital Ramón y Cajal, Carretera de Colmenar, Km 9, 28034 Madrid, SPAIN; idelcastillo.hrc@salud.madrid.org

\section{REFERENCES}

1 Petit C, Levilliers J, Hardelin JP. Molecular genetics of hearing loss. Annu Rev Genet 2001;35:589-646.

2 Friedman TB, Griffith AJ. Human nonsyndromic sensorineural deafness. Annu Rev Genomics Hum Genet 2003:4:341-402.

3 Van Camp G, Smith RJH. Hereditary Hearing Loss home page. http:// www.via.ac.be/dnalab/hhh.

4 Kenneson A, Van Naarden Braun K, Boyle C. GJB2. (connexin 26) variants and nonsyndromic sensorineural hearing loss: a HuGE review, Genet Med, 2002;4:258-74.

5 Kelsell DP, Dunlop J, Stevens HP, Lench NJ, Liang JN, Parry G, Mueller RF, Leigh IM. Connexin 26 mutations in hereditary nonsyndromic sensorineural deafness. Nature 1997;387:80-3.

6 Willecke K, Eiberger J, Degen J, Eckardt D, Romualdi A, Guldenagel M, Deutsch $U$, Sohl G. Structural and functional diversity of connexin genes in the mouse and human genome. Biol Chem 2002;383:725-37.

7 Forge A, Becker D, Casalotti S, Edwards J, Marziano N, Nickel R. Connexins and gap junctions in the inner ear. Audiol Neurootol 2002;7:141-5.

8 Cohen-Salmon M, Maxeiner S, Kruger O, Theis M, Willecke K, Petit C. Expression of the connexin43- and connexin45-encoding genes in the developing and mature mouse inner ear. Cell Tissue Res 2004;316:15-22. 
9 Kikuchi T, Adams JC, Miyabe Y, So E, Kobayashi T. Potassium ion recycling pathway via gap junction systems in the mammalian cochlea and its interruption in hereditary nonsyndromic deafness. Med Electron Microsc 2000;33:51-6

10 Connexin-Deafness home page. http://www.crg.es/deafness.

11 Lerer I, Sagi M, Ben-Neriah Z, Wang T, Levi H, Abeliovich D. A deletion mutation in GJB6 cooperating with a GJB2 mutation in trans in non-syndromic deafness: a novel founder mutation in Ashkenazi jews. Hum Mutat 2001:18:460

12 del Castillo I, Villamar M, Moreno-Pelayo MA, del Castillo FJ, Alvarez A Telleria D, Menendez I, Moreno F. A deletion involving the connexin 30 gene in nonsyndromic hearing impairment. N Engl J Med 2002;346:243-9.

13 Pallares-Ruiz N, Blanchet $P$, Mondain M, Claustres M, Roux AF. A large deletion including most of $G J B 6$ in recessive non syndromic deafness: a digenic effect? Eur J Hum Genet 2002;10:72-6.

14 del Castillo I, Moreno-Pelayo MA, del Castillo FJ, Brownstein Z, Marlin S, Adina Q, Cockburn DJ, Pandya A, Siemering KR, Chamberlin GP, Ballana E Wuyts W, Maciel-Guerra AT, Alvarez A, Villamar M, Shohat M, Abeliovich D, Dahl HHM, Estivill X, Gasparini P, Hutchin T, Nance WE, Sartorato EL, Smith RJH, Van Camp G, Avraham KB, Petit C, Moreno F. Prevalence and evolutionary origins of the del(GJB6-D13S1830) mutation in the DFNB1 locus in hearing impaired subjects: a multicenter study. Am J Hum Genet 2003;73:1452-8.

15 Gualandi F, Ravani A, Berto A, Burdo S, Trevisi P, Ferlini A, Martini A Calzolari E. Occurrence of del(GJB6-D13S1830) mutation in Italian nonsyndromic hearing loss patients carrying a single GJB2 mutated allele. Acta Otolaryngol Suppl 2004;552:29-34.

16 Pandya A, Arnos KS, Xia XJ, Welch KO, Blanton SH, Friedman TB, Garcia Sanchez G, Liu MD XZ, Morell R, Nance WE. Frequency and distribution of GJB2 (connexin 26) and GJB6 (connexin 30) mutations in a large North American repository of deaf probands. Genet Med 2003;5:295-303.

17 Stevenson VA, Ito M, Milunsky JM. Connexin-30 deletion analysis in connexin-26 heterozygotes. Genet Test 2003;7:151-4.

18 Wu BL, Kenna M, Lip V, Irons M, Platt O. Use of a multiplex PCR/sequencing strategy to detect both connexin 30 (GJB6) $342 \mathrm{~kb}$ deletion and connexin 26 (GJB2) mutations in cases of childhood deafness. Am J Med Genet 2003; 121A: 102-8

19 Erbe CB, Harris KC, Runge-Samuelson CL, Flanary VA, Wackym PA. Connexin 26 and connexin 30 mutations in children with nonsyndromic hearing loss. Laryngoscope 2004; 114:607-11.

20 Bolz H, Schade G, Ehmer S, Kothe C, Hess M, Gal A. Phenotypic variability of non-syndromic hearing loss in patients heterozygous for both c. $35 \mathrm{del} G$ of GJB2 and the 342-kb deletion involving GJB6. Hear Res 2004;188:42-6.

21 Gunther B, Steiner A, Nekahm-Heis D, Albegger K, Zorowka P, Utermann G, Janecke A. The 342-kb deletion in GJB6 is not present in patients with nonsyndromic hearing loss from Austria. Hum Mutat 2003;22:180.

22 Tekin M, Duman T, Bogoclu G, Incesulu A, Comak E, Ilhan I, Akar N. Spectrum of GJB2 mutations in Turkey comprises both Caucasian and Oriental variants: roles of parental consanguinity and assortative mating. Hum Mutat 2003;21:552-3.

23 Uyguner O, Emiroglu M, Uzumcu A, Hafiz G, Ghanbari A, Baserer N, Yuksel-Apak M, Wollnik B. Frequencies of gap- and tight-junction mutations in
Turkish families with autosomal-recessive non-syndromic hearing loss. Clin Genet 2003;64:65-9.

24 Liu XZ, Xia XJ, Ke XM, Ouyang XM, Du LL, Liu YH, Angeli S, Telischi FF, Nance WE, Balkany T, Xu LR. The prevalence of connexin 26 (GJB2) mutations in the Chinese population. Hum Genet 2002:111:394-7.

25 Dib C, Faure S, Fizames C, Samson D, Drouot N, Vignal A, Millasseau P, Marc S, Hazan J, Seboun E, Lathrop M, Gyapay G, Morissette J, Weissenbach J. A comprehensive genetic map of the human genome based on 5,264 microsatellites. Nature 1996;380:152-4

26 Kibar Z, Lafreniere RG, Chakravarti A, Wang J, Chevrette M, Der Kaloustian VM, Rouleau GA. A radiation hybrid map of 48 loci including the Clouston Hidrotic Ectodermal Dysplasia locus in the pericentromeric region of chromosome 13q. Genomics 1999;56:127-30.

27 RepeatMasker Server home page. http://www.repeatmasker.org.

28 Lautermann J, ten Cate WJ, Altenhoff P, Grümmer R, Traub O, Frank HG Jahnke K, Winterhager E. Expression of the gap-junction connexins 26 and 30 in the rat cochlea. Cell Tissue Res 1998;294:415-20.

29 Lautermann J, Frank HG, Jahnke K, Traub O, Winterhager E. Developmental expression patterns of connexin26 and -30 in the rat cochlea. Dev Genet 1999:25:306-11.

30 Dahl E, Manthey D, Chen Y, Schwarz HJ, Chang YS, Lalley PA, Nicholson BJ, Willecke K. Molecular cloning and functional expression of mouse connexin30, a gap junction gene highly expressed in adult brain and skin. J Biol Chem 1996:271:17903-10.

31 Grifa A, Wagner C, D’Ambrosio L, Melchionda S, Bernardi F, Lopez-Bigas N, Rabionet R, Arbones M, Della Monica M, Estivill X, Zelante L, Lang F, Gasparini P. Mutations in GJB6 cause nonsyndromic autosomal dominant deafness at DFNA3 locus. Nat Genet 1999:23:16-18.

32 Teubner B, Michel V, Pesch J, Lautermann J, Cohen-Salmon M, Sohl G, Jahnke K, Winterhager E, Herberhold C, Hardelin JP, Petit C, Willecke K. Connexin30 (Gjb6)-deficiency causes severe hearing impairment and lack of endocochlear potential. Hum Mol Genet 2003;12:13-21.

33 Michel V, Hardelin JP, Petit C. Molecular mechanism of a frequent genetic form of deafness. N Engl J Med 2003:349:716-17.

34 Feldmann D, Denoyelle F, Chauvin P, Garabedian EN, Couderc R, Odent S, Joannard A, Schmerber S, Delobel B, Leman J, Journel H, Catros $H$, Le Marechal C, Dollfus H, Eliot MM, Delaunoy JP, David A, Calais C, DrouinGarraud V, Obstoy MF, Bouccara D, Sterkers O, Huy PT, Goizet C, Duriez F, Fellmann F, Helias J, Vigneron J, Montaut B, Lewin P, Petit C, Marlin S. Large deletion of the GJB6 gene in deaf patients heterozygous for the GJB2 gene mutation: genotypic and phenotypic analysis. Am J Med Genet 2004; 127A:263-7.

35 Roux AF, Pallares-Ruiz N, Vielle A, Faugere V, Templin C, Leprevost D, Artieres F, Lina G, Molinari N, Blanchet P, Mondain M, Claustres $M$. Molecular epidemiology of DFNB1 deafness in France. BMC Med Genet 2004;5:5.

36 Deininger PL, Batzer MA. Alu repeats and human disease. Mol Genet Metab 1999:67:183-93.

37 Chen J, Yu L, Li D, Gao Q, Wang J, Huang X, Bi G, Wu H, Zhao S. Human CRYL1, a novel enzyme-crystallin overexpressed in liver and kidney and downregulated in $58 \%$ of liver cancer tissues from 60 Chinese patients, and four new homologs from other mammalians. Gene 2003;302:103-13. 